\title{
Cystic Echinococcosis: Knowledge, Attitude, and Practices (KAP) among Surgically Operated Cases in Fars Province, Southern Iran
}

\author{
Zahra Hosseini, ${ }^{1}$ Reza Shahriarirad $\mathbb{D}^{2},{ }^{2}$ and Bahador Sarkari $\mathbb{D}^{1,3}$ \\ ${ }^{1}$ Department of Parasitology and Mycology, School of Medicine, Shiraz University of Medical Sciences, Shiraz, Iran \\ ${ }^{2}$ Student Research Committee, Shiraz University of Medical Sciences, Shiraz, Iran \\ ${ }^{3}$ Basic Sciences in Infectious Diseases Research Center, Shiraz University of Medical Sciences, Shiraz, Iran \\ Correspondence should be addressed to Bahador Sarkari; sarkarib@sums.ac.ir
}

Received 6 March 2021; Revised 1 April 2021; Accepted 2 April 2021; Published 8 April 2021

Academic Editor: José F. Silveira

Copyright (C) 2021 Zahra Hosseini et al. This is an open access article distributed under the Creative Commons Attribution License, which permits unrestricted use, distribution, and reproduction in any medium, provided the original work is properly cited.

\begin{abstract}
Introduction. Cystic echinococcosis (CE) is a neglected zoonotic disease caused by Echinococcus granulosus with major health and economic burden. The information on how the community members perceive the disease is crucial in order to recommend an effective preventive and control plan. The current study is aimed at finding out knowledge, attitude, and practices (KAP) of surgically operated cases of hydatid cyst in educational hospitals of Shiraz in Fars Province, southern Iran, toward the CE. Methods. A cross-sectional survey was conducted among $180 \mathrm{CE}$ patients who underwent surgery due to CE. Using a well-designed questionnaire, a telephone-based survey was carried out to collect the data. The contents of the questionnaire included basic personal information and questions related to the participants' knowledge, attitude, and behavioral patterns toward CE. Univariate and then multivariate linear regression analyses were used to identify factors associated with the KAP. Unstandardized regression coefficients $(\beta)$ and odds ratios (ORs) and their 95\% confidence intervals (CIs) were used to quantify the associations between variables and KAP. Results. A total of 180 CE patients with a mean age of $35.64( \pm 17.59)$ years were recruited. The mean score of participant's knowledge was $8.7(\mathrm{SD}=2.8, \mathrm{range}$ : 0 - 17$)$, whereas these scores were $1.3(\mathrm{SD}=0.7$, range $0-2)$ for attitude and $1.2(\mathrm{SD}=1.0$, range $0-4)$ for practice. Findings of the study demonstrated that 20 of the participants $(11.1 \%)$ had good knowledge towards CE, $82(45.6 \%)$ demonstrated a positive attitude, and $57(47.5 \%)$ without having dogs demonstrated a good practice towards CE (score $=2 / 2$ ), while from 60 dog owners, only 7 (11.6\%) participants demonstrated good practice (score 3 and 4/4). Factors that were associated with knowledge were age $(\mathrm{OR}=-0.49, P$ value $=0.001)$ and educational level $(\mathrm{OR}=0.668, P$ value $=0.001)$, where higher age was associated with lower knowledge and also higher educational levels were associated with higher knowledge regarding hydatid cyst. Regarding attitude, only living location had a significant association with participants' attitude where those who were living in urban areas demonstrating a more positive attitude towards $\mathrm{CE}(\mathrm{OR}=0.261, P$ value $=0.022)$. The practice of the participants was grouped into dog owners and participants with no dogs, in which among participants who did not own a dog, those living in urban areas demonstrating weaker practice towards $\mathrm{CE}(\mathrm{OR}=-0.491, P$ value $>0.001)$. Moreover, a lack of counseling of patients after the surgery on how to prevent reinfection was noticed. Conclusion. Findings of the study revealed that the CE patients in southern Iran had poor knowledge and attitude toward the disease, and their practice may help in maintaining the disease in the community. Health education is highly needed to increase community awareness and to prevent and control this neglected parasitic infection in the area.
\end{abstract}

\section{Introduction}

Cystic echinococcosis (CE) or hydatid cyst is an infectious disease that affects both humans and animals. Livestock (especially sheep) serves as intermediate hosts for the transmission of $\mathrm{CE}$, while canids, mainly dog, act as the definitive hosts. Human acquires the disease by accidental ingestion of eggs existing in dog feces $[1,2]$. 
$\mathrm{CE}$ is a major health and economic challenge in the Middle East countries, including Iran where about $1 \%$ of all hospital surgeries are accounted for this disease [3-5]. The overall seroprevalence of CE in Iran is reported to be $4.2 \%$ with the highest prevalence in the South area with $5.8 \%$ and the least in the central area with $2.2 \%$ prevalence rate [6]. CE is one of the most important parasitic diseases in Fars Province in the south of Iran $[5,7,8]$. Fars Province is the center of agriculture and animal husbandry in Iran, and one of the most important and populated tribal nomads (Qashqai) resides in this area. The province is endemic focus for several parasitic diseases including visceral and cutaneous leishmaniasis $[9,10]$. In a study by Shahriarirad et al. in Fars Province, a total of $501 \mathrm{CE}$ surgical cases were recorded during 15 years, corresponding to an average annual incidence of 33.4 and a surgical incidence rate of 0.74/100,000 population [5].

To introduce and implement effective control measures, knowing the disease mode of transmission and its characteristics is crucial. According to the KAP theory, the controlling of the disease in the community is generally affected by people's knowledge, attitude, and practices (KAP) concerning the disease $[11,12]$. Public education is considered as one of the most important measures that can help control the $\mathrm{CE}$, as has been the case in other diseases [13]. Hence, with CE prevention and control programs being a necessity, a well-enough knowledge of the disease accompanied by community cooperation can play a significant role in the success of these programs. The current study is aimed at determining the level of knowledge, attitude, and practices of patients who underwent surgery for hydatid cyst in Fars Province, southern Iran, about the risk factors for hydatid cyst.

\section{Materials and Methods}

2.1. Study Design and Participants. In this cross-sectional study, a list of hospitalized CE patients during a period of 6 years (2014-2020) was obtained at the main university-affiliated and referral hospitals in Shiraz, capital of Fars Province. Sample size estimation was done by the Med-Calc statistical software with an error of $5 \%$ and a power of $90 \%$. The recruitment method was voluntary participation, and individuals unwilling to participate were excluded from the study. Also, subjects were assured that the results would be reviewed as a group and that the confidentiality of their responses would be preserved.

Only cases with a final diagnosis of any type of CE at hospital discharge which were recorded with a unique disease code (based on the ICD-9 and ICD-10: International Classification of Diseases; 122.9 and 122.8 for ICD9; B67.8, K77.0, B67.9, and J99.8 for ICD10) were included in the data analysis. The data collection tool in this study consisted of a standard and research designed questionnaire, in which each patient was contacted by telephone call and was asked a series of questions by the interviewer.

2.2. Ethical Consideration. The study was approved by the Ethics Committee of Shiraz University of Medical Sciences
(Ref. No. IR.sums.med.rec.1399.419). Participants who verbally consented to be included in our study were enrolled.

2.3. Data Collection. Data collection was done through a researcher-developed questionnaire in which consisted of the following sections:

(1) Demographic variables including gender, age, province of residence, educational level, and occupation along with other factors regarding the patient's history of $\mathrm{CE}$

(2) Knowledge, attitude, and practice questions, which consisted of 18 questions assessing the participants' KAP towards CE

(3) Seven additional questions including "Do you keep dogs in your area?" "Do you own livestock? (cattle, cow, sheep)" "Have you ever seen a hydatid cyst in an animal's liver, lungs, or abdomen?" "Did your doctor or nurse give you information about hydatid cysts?" "Has anyone in your family been infected with hydatid cyst" "How severe or fatal do you think this disease is?" "What is your source of information about hydatid cysts?"

A correct answer was assigned as one point while an incorrect answer received no points.

2.4. Data Analysis. All the statistical analyses were performed, using Microsoft Excel 2007 (Microsoft Corp., Redmond, USA) and statistical package for social sciences (SPSS Inc., Chicago, Illinois, USA, version 26.0). Univariate and then multivariate linear regression analyses were used to identify factors associated with participants' KAP. Unstandardized regression coefficients $(\beta)$ and odds ratios (ORs) and their 95\% confidence intervals (CIs) were used to quantify the associations between variables and KAP. The statistical significance level was set at $P<0.05$.

\section{Results}

A total of $180 \mathrm{CE}$ patients were recruited in this study and contacted regarding their KAP towards $\mathrm{CE}$. The mean age of the participants was $35.64( \pm 17.59)$. Table 1 demonstrates the demographic features of the participants in our study.

The mean score of the participants' knowledge toward CE was 8.7 ( \pm 2.8 , range: $0-17$ ), the mean score of attitude was $1.3( \pm 0.7$, range $0-2)$, and the mean score of practice was $1.2( \pm 1.0$, range $0-4)$ for dog owners and $1.4( \pm 0.7$, range 0 -2) for participants who did not own dogs. Table 2 shows the details of participants' KAP toward CE, based on the questions asked.

To further review and analyze the findings, the KAP of the participants were categorized into good, moderate, and weak. The knowledge score (ranging from 0-17) was grouped as score range of $0-5$ as weak/low knowledge, 6-11 as moderate knowledge, and 12-17 as good knowledge towards CE. The findings demonstrated that $23(12.8 \%)$ of the participants had low knowledge, while 137 (76.1\%) had moderate knowledge, and 20 (11.1\%) had good knowledge of CE. 
TABle 1: Demographic features of participants in the study.

\begin{tabular}{|c|c|c|}
\hline \multirow{2}{*}{ Variable } & \multicolumn{2}{|c|}{ Frequency } \\
\hline & Number & Percentage \\
\hline \multicolumn{3}{|l|}{ Age group } \\
\hline $10-20$ & 42 & 23.3 \\
\hline $21-30$ & 39 & 21.7 \\
\hline $31-40$ & 28 & 15.6 \\
\hline $41-50$ & 27 & 15 \\
\hline $51-60$ & 28 & 15.6 \\
\hline$>60$ & 16 & 8.9 \\
\hline \multicolumn{3}{|l|}{ Gender } \\
\hline Male & 91 & 50.6 \\
\hline Female & 89 & 49.4 \\
\hline \multicolumn{3}{|l|}{ Occupation } \\
\hline Unemployed & 102 & 56.7 \\
\hline Self-employed & 43 & 23.9 \\
\hline Freelance & 14 & 7.8 \\
\hline Retired & 8 & 4.4 \\
\hline Nongovernmental employee & 7 & 3.9 \\
\hline Student & 4 & 2.2 \\
\hline Government employee & 2 & 1.1 \\
\hline \multicolumn{3}{|l|}{ Educational level } \\
\hline Illiterate & 17 & 9.4 \\
\hline Reading and writing & 25 & 13.9 \\
\hline Under high school diploma & 78 & 43.3 \\
\hline Diploma & 42 & 23.3 \\
\hline University degree & 18 & 10 \\
\hline \multicolumn{3}{|l|}{ Residence } \\
\hline Urban & 88 & 48.9 \\
\hline Rural & 92 & 48.9 \\
\hline \multicolumn{3}{|l|}{ Marital status } \\
\hline Single & 72 & 40 \\
\hline Married & 108 & 60 \\
\hline \multicolumn{3}{|c|}{ Number of individuals in the household } \\
\hline$<5$ & 118 & 65.6 \\
\hline$\geq 5$ & 62 & 34.4 \\
\hline \multicolumn{3}{|l|}{ Living location } \\
\hline Apartment & 21 & 11.7 \\
\hline House/villa & 159 & 88.3 \\
\hline \multicolumn{3}{|l|}{ Year of operation for CE } \\
\hline 2020 & 51 & 28.3 \\
\hline 2019 & 58 & 32.2 \\
\hline 2018 & 35 & 19.4 \\
\hline 2017 & 30 & 16.7 \\
\hline 2016 & 5 & 2.8 \\
\hline 2014 & 1 & 0.6 \\
\hline \multicolumn{3}{|l|}{ Location of $\mathrm{CE}$} \\
\hline Lung & 118 & 65.6 \\
\hline Liver & 59 & 32.8 \\
\hline Other locations & 3 & 1.7 \\
\hline
\end{tabular}

TABle 1: Continued.

\begin{tabular}{lcc}
\hline \multirow{2}{*}{ Variable } & \multicolumn{2}{c}{ Frequency } \\
& Number & Percentage \\
\hline Number of CE & & \\
One & 68 & 41 \\
Two & 58 & 34.9 \\
More than 2 & 40 & 24.1 \\
\hline
\end{tabular}

Attitude score ranged from 0 to 2 . Based on the results of our study, $82(45.6 \%)$ of the participants demonstrated a positive attitude towards CE, while $72(40 \%)$ demonstrated moderate, and 26 (14.4\%) demonstrated a negative attitude towards CE. Based on the participants' practice score, 57 (47.5\%) of the participants without dogs demonstrated a good practice towards CE (score $=2 / 2)$, while $50(41.7 \%)$ of them demonstrated moderate $($ score $=1 / 2)$ and $13(10.8 \%)$ demonstrated a weak practice towards CE $($ score $=0 / 2)$. Regarding the 60 dog owners, only 7 (11.6\%) demonstrated good practice (score 3 and 4/4), while $12(20 \%)$ demonstrated moderate practice $($ score $=2 / 4)$, and $41(68.3 \%)$ demonstrated weak practice (score $=0$ and $1 / 4$ ) towards CE.

To evaluate the effect of the variables of our study in the participants' KAP, multiple linear regression analysis was used, and the results are given in Table 3 .

As demonstrated in Table 3, factors that were associated with knowledge were age $(\mathrm{OR}=-0.49, P$ value $=0.001)$ and educational level $(\mathrm{OR}=0.668, P$ value $=0.001)$, where higher age was associated with lower knowledge and also higher educational levels were associated with higher knowledge regarding hydatid cyst. Regarding attitude, only living location had a significant association, with participants living in urban areas demonstrating a more positive attitude towards $\mathrm{CE}(\mathrm{OR}=0.261, P$ value $=0.022)$.

The participants were also asked a series of additional questions, which are reported in Table 4. The sources of information for most of the participants have been social media and the internet. Moreover, a lack of counseling of patients after the surgery on how to prevent CE reinfection was noticed.

\section{Discussion}

In the current study, the KAP of CE patients towards the disease was assessed. As our results show, knowledge, attitude, and practice of the CE patients were relatively low with only $11.1 \%$ of the participants demonstrating good knowledge, $45.6 \%$ demonstrating a positive attitude, and $11.6 \%$ of dog owners and $47.5 \%$ of participants with no dog demonstrating suitable practice towards CE.

Our results are similar to the findings of Abdulhameed et al., a study on surgical cases of CE in Iraq, which reported that $72 \%$ of the participants had not heard of CE and $57 \%$ did not know the mode of transmission of hydatid cysts, even after surgery for the disease [14].

In a community based cross-sectional study by $\mathrm{Dan} \mathrm{Li}$ et al. [1] in Xiahe County, in China, $65.9 \%$ of the participants have heard the name of CE. A study in Pakistan by Khan 
TABLE 2: Questionnaire items and responses regarding KAP among participants with a history of hydatid cyst surgery.

\begin{tabular}{|c|c|c|}
\hline \multirow{2}{*}{ Question } & \multirow{2}{*}{ Answers } & Frequency \\
\hline & & Number Percentage \\
\hline
\end{tabular}

Knowledge

(1) Have you had heard about hydatid cyst before you were infected with it?

$\begin{array}{ccc}\text { Yes }^{*} & 8 & 4.4 \\ \text { No } & 172 & 95.6\end{array}$

(2) What are the symptoms of a hydatid cyst?

$\begin{array}{ccc}\text { Gastrointestinal symptoms* } & 73 & 40.6 \\ \text { Liver symptoms* } & 41 & 22.8 \\ \text { Pulmonary symptoms* } & 104 & 57.8 \\ \text { Cerebral symptoms* } & 9 & 5 \\ \text { Do not know } & 43 & 23.9\end{array}$

(3) Do you know which animal is the source and reservoir of hydatid cyst?

$\begin{array}{ccc}\text { Dog* } & 131 & 72.8 \\ \text { Cat } & 15 & 8.3 \\ \text { Sheep } & 9 & 5 \\ \text { Do not know } & 25 & 13.9\end{array}$

(4) Do you know how a person can get infected with hydatid cyst?

$\begin{array}{ccc}\text { Yes* }^{*} & 122 & 67.8 \\ \text { No } & 58 & 32.2\end{array}$

(5) Do you know what causes hydatid cyst disease?

$\begin{array}{ccc}\text { Parasite }^{*} & 127 & 70.6 \\ \text { Microbe } & 16 & 8.9 \\ \text { Virus } & 1 & 0.6 \\ \text { Do not know } & 36 & 20\end{array}$

(6) Do you know the route of transmission of hydatid cyst?

$\begin{array}{ccc}\text { Yes* }^{*} & 131 & 72.8 \\ \text { No } & 49 & 27.2\end{array}$

(7) Do you know how to prevent hydatid cysts?

$\begin{array}{ccc}\text { Yes* }^{*} & 125 & 69.4 \\ \text { No } & 55 & 30.6\end{array}$

(8) Do you think this disease is heritable?

$\begin{array}{ccc}\text { Yes } & 18 & 10 \\ \text { No* }^{*} & 162 & 90\end{array}$

(9) To what extent do you think measures can be taken to prevent the disease?*

$\begin{array}{ccc}\text { Very high }^{*} & 93 & 51.7 \\ \text { High* }^{*} & 63 & 35 \\ \text { Low } & 21 & 11.7 \\ \text { Very low } & 3 & 1.7\end{array}$

(10) Did you know that playing with dogs can put you at risk for hydatid cyst disease?

\begin{tabular}{ccc} 
Yes* & 142 & 78.9 \\
No & 5 & 2.8 \\
Do not know & 33 & 18.3 \\
\hline
\end{tabular}

TABle 2: Continued.

\begin{tabular}{|c|c|c|}
\hline \multirow{2}{*}{ Question } & \multirow{2}{*}{ Answers } & Frequency \\
\hline & & Number Percentage \\
\hline
\end{tabular}

(11) Is hydatid cyst transmitted to humans through eating the meat or liver of animals (sheep, cattle, goats)?*

$\begin{array}{ccc}\text { Yes } & 131 & 72.8 \\ \text { No* } & 12 & 6.7 \\ \text { not know } & 37 & 20.6\end{array}$

(12) Is hydatid cyst transmitted through vegetables that are not well washed?

$\begin{array}{ccc}\text { Yes* }^{*} & 162 & 90 \\ \text { No } & 2 & 1.1 \\ \text { Do not know } & 16 & 8.9\end{array}$

(13) Can a person who gets hydatid cyst get the disease again?

$\begin{array}{ccc}\text { Yes* }^{*} & 74 & 41.1 \\ \text { No } & 31 & 17.2 \\ \text { Do not know } & 75 & 41.7\end{array}$

(14) Is hydatid cyst transmitted in children through play with soil?

$\begin{array}{ccc}\text { Yes* }^{*} & 129 & 71.7 \\ \text { No } & 13 & 7.2 \\ \text { not know } & 38 & 21.1\end{array}$

Attitude

(15) In your opinion, how much luck is involved in the development of hydatid cysts?

$\begin{array}{ccc}\text { A lot } & 63 & 35 \\ \text { Not much* }^{*} & 117 & 65\end{array}$

(16) In case of infection, how much do you think traditional healers and local remedies can help treat you?

$\begin{array}{ccc}\text { Very high } & 9 & 5 \\ \text { High } & 52 & 28.9 \\ \text { Low* }^{*} & 68 & 37.8 \\ \text { Very low* } & 51 & 28.3\end{array}$

Practice

(17) What is your source of drinking water?

$\begin{array}{ccc}\text { Tap water* } & 125 & 69.4 \\ \text { Well } & 41 & 22.8 \\ \text { Fountain } & 14 & 7.8\end{array}$

(18) Do you treat your dog for parasites?

$\begin{array}{ccc}\text { Yes* }^{*} & 22 & 12.2 \\ \text { No } & 38 & 21.1 \\ \text { Do not own a dog } & 120 & 66.7\end{array}$

(19) If you keep dogs at home, do you use the liver, lungs, or other parts of sheep and goats to feed them?

$\begin{array}{ccc}\text { Yes } & 43 & 23.9 \\ \text { No* }^{*} & 17 & 9.4 \\ \text { Do not own } & 120 & 66.7\end{array}$

(20) Do you sometimes butcher at home?

$\begin{array}{ccc}\text { Yes } & 112 & 62.2 \\ \text { No* }^{*} & 68 & 37.8\end{array}$

* indicates the desired answer. 
TABLE 3: Linear regression analysis of factors associated with KAP among participants with a history of hydatid cyst surgery.

\begin{tabular}{lccccc}
\hline Model & Beta & $T$ & $P$ value & $R$ & $R^{2}$ \\
\hline Knowledge & & & & & \\
$\quad$ Age & -0.49 & -3.240 & 0.001 & & \\
Education (illiterate) & 0.668 & 3.309 & 0.001 & 0.433 & 0.188 \\
Residence (urban) & -0.378 & -0.940 & 0.349 & & \\
Marital status (single) & 0.686 & 1.321 & 0.188 & & \\
Attitude & & & & & \\
Age & 0.001 & 0.339 & 0.735 & & \\
Education (illiterate) & 0.035 & 0.627 & 0.531 & 0.175 & 0.031 \\
Residence (urban) & 0.261 & 2.318 & 0.022 & & \\
Marital status (single) & -0.081 & -0.559 & 0.577 & & \\
Practice (no dog) & & & & & \\
Age & -0.004 & -1.030 & 0.305 & & \\
Education (illiterate) & 0.032 & 0.524 & 0.601 & 0.440 & 0.194 \\
Residence (urban) & -0.491 & -4.174 & $>0.001$ & & \\
Marital status (single) & -0.180 & -1.215 & 0.227 & & \\
Practice (dog owner) & & & & & \\
Age & -0.016 & -1.306 & 0.197 & & \\
Education (illiterate) & 0.070 & 0.459 & 0.648 & 0.342 & 0.117 \\
Residence (urban) & -0.303 & -0.971 & 0.336 & & \\
Marital status (single) & 0.157 & 0.392 & 0.696 & & \\
\hline
\end{tabular}

et al. [15], regarding the knowledge, attitudes, and practices on the occurrence of CE in butchers and dog owners in both urban and rural areas of Rawalpindi/Islamabad regions, showed that only $4.1 \%$ of people have heard about the disease. In a study regarding KAP towards CE in China by Yin et al. [16], the findings indicated that the KAP rate for all participants was $72.6 \%, 6.4 \%, 95.0 \%$, and $75.8 \%$ for $\mathrm{KAP}, K, A$, and $P$, respectively. The KAP rates were significantly different among different age and gender groups.

In a study in Ethiopia [17] on risk factors on public awareness, attitude, and practices of CE, only $4.29 \%$ of pastoralists responded that they were aware of the occurrence of the disease in human, but none of them were knowledgeable on its sources and transmission.

A cross-sectional survey by Ahmed et al. [18], in three villages around the city of Tambool in Central Sudan, showed that $68.7 \%$ of the participants had never heard of the disease.

A study in Turkey [19] on 151 farmers regarding KAP towards CE showed that the knowledge level of livestock farmers is very low (21.9\%). A study by Ozlu et al. [20] on 1,045 cattle farmers in Erzurum in Turkey showed that the increase in education status, size of the enterprise, and monthly income of cattle farmers were related to an increase in knowledge, attitude, and practices regarding zoonotic diseases. However, it was found that the positive knowledge and attitudes of the cattle farmers could not be transformed into positive practices evenly.

Singh et al. [21] conducted a study to find out the knowledge, attitude, and practices of livestock farmers regarding zoonoses in India where the low level of education and being
TABLE 4: Additional questions regarding participants' perspective towards CE.

\begin{tabular}{lcc}
\hline \multirow{2}{*}{ Questions } & \multicolumn{2}{c}{ Frequency } \\
& Number & Percentage \\
\hline (1) Do you keep dogs in your area? & 60 & 33.3 \\
Yes & 120 & 66.7 \\
No & \\
(2) Do you own livestock? (cattle, cow, sheep) & \\
Yes & 66 & 36.7 \\
No & 114 & 63.3 \\
(3) Have you ever seen a hydatid cyst in an animal's liver, lungs, or \\
abdomen? \\
Yes \\
No \\
(
\end{tabular}

(4) Did your doctor or nurse give you information about hydatid cysts?

$\begin{array}{lcc}\text { Yes } & 166 & 92.2 \\ \text { No } & 14 & 7.8\end{array}$

(5) Has anyone in your family been infected with hydatid cyst?

$\begin{array}{lcc}\text { Yes } & 5 & 2.8 \\ \text { No } & 175 & 97.2\end{array}$

(6) How severe or fatal do you think this disease is?

$\begin{array}{lcc}\text { Very high } & 93 & 51.7 \\ \text { High } & 63 & 35 \\ \text { Low } * & 21 & 11.7 \\ \text { Very low* } & 3 & 1.7\end{array}$

(7) What is your source of information about hydatid cysts?

$\begin{array}{lcc}\text { Internet and social media } & 71 & 39.4 \\ \text { Scientific articles and books } & 44 & 24.4 \\ \text { Healthcare professionals and doctors } & 165 & 91.7 \\ \text { None } & 12 & 6.7\end{array}$

a cattle farmer were negatively associated with the farmer's knowledge on zoonotic diseases.

Our results are also in line with the findings of other questionnaire surveys conducted in Libya and Morocco [22, 23], which found that the majority of respondents had limited to no information about the transmission of CE. Increasing knowledge and information regarding diseases is an essential step towards the management and prevention of the disease.

Among the noteworthy results of our study is that only $11.6 \%$ of dog owners demonstrated suitable practice towards CE. Studies from southern Iran regarding free-roaming and stray dogs reported a prevalence of $10.7 \%$ to $36.19 \%$ for $E$. granulosus infection in dogs $[24,25]$. The close contact of people with dogs, combined with feeding offal, along with environmental contamination enhances the likelihood of transmission of this zoonotic tapeworm to humans, especially the children $[7,26,27]$.

In our study, $62.5 \%$ of the participants reported slaughtering and butchering at home. Abdulhameed et al. reported that around 50\% of surgical cases of CE in Iraq performed home slaughtering and butchering [14]. Many studies have 
highlighted the effect of the common practice of slaughtering animals by householders in or near their homes on CE infection $[28,29]$. It is obvious that under the supervision of a veterinarian, the slaughter of animals in a slaughterhouse reduces the ability to complete the life cycle of Echinococcus by ensuring proper disposal of infected offal [30].

In partnership with the veterinary authorities, the health authorities in Iran and also in any CE-endemic areas need to establish and introduce educational programs on echinococcosis for farmers, pet owners, and the general population. These initiatives should include information on the need for deworming of dogs; better hygiene for food preparation; animal slaughter at home, including strict instructions on how to extract infected offal; how to disrupt the life cycle of Echinococcus and how to avoid its development; and practices to reduce the dog infection.

\section{Conclusion}

Findings of the current study revealed that the CE patients in southern Iran had poor knowledge and attitude toward the disease, and their improper practice may help in maintaining the disease in the community. Successful education and awareness programs in the community for the prevention and control of $\mathrm{CE}$ can be of great benefit. Improving the degree of awareness of the community about CE is the groundwork for the prevention and management of the diseases which in turn improves the attitude of people in the community.

\section{Data Availability}

The nominal and ordinal data used to support the findings of this study are available from the corresponding author upon request.

\section{Conflicts of Interest}

The authors declare that they have no conflicts of interest.

\section{Authors' Contributions}

BS and RS designed the study. ZH and RS were involved in data collection and data analysis. RS prepared the manuscript draft. BS edited and approved the draft. All authors read and approved the final version of the manuscript.

\section{Acknowledgments}

This study was the subject of the MD dissertation of Dr. Zahra Hosseini. The study was financially supported by the office of Vice-Chancellor for Research, Shiraz University of Medical Sciences (Grant No. 97-01-01-18960). Technical assistance of Sepehr Shahriarirad is acknowledged.

\section{References}

[1] D. Li, Q. Gao, J. Liu et al., "Knowledge, attitude, and practices (KAP) and risk factors analysis related to cystic echinococcosis among residents in Tibetan communities, Xiahe County,
Gansu Province, China," Acta Tropica, vol. 147, pp. 17-22, 2015.

[2] C. M. Coyle and T. Junghanss, "Cystic Echinococcosis," in Hunter's Tropical Medicine and Emerging Infectious Diseases, pp. 946-953, Elsevier, 2020.

[3] P. Deplazes, L. Rinaldi, C. A. Alvarez Rojas et al., "Global distribution of alveolar and cystic echinococcosis," Advances in Parasitology, vol. 95, pp. 315-493, 2017.

[4] M. Fasihi Harandi, C. M. Budke, and S. Rostami, "The monetary burden of cystic echinococcosis in Iran," PLoS Neglected Tropical Diseases, vol. 6, no. 11, article e1915, 2012.

[5] R. Shahriarirad, A. Erfani, M. Eskandarisani, M. Rastegarian, H. Taghizadeh, and B. Sarkari, "Human cystic echinococcosis in southwest Iran: a 15-year retrospective epidemiological study of hospitalized cases," Tropical Medicine and Health, vol. 48 , no. $1,2020$.

[6] H. R. Khalkhali, M. Foroutan, S. Khademvatan et al., "Prevalence of cystic echinococcosis in Iran: a systematic review and meta-analysis," Journal of Helminthology, vol. 92, no. 3, pp. 260-268, 2018.

[7] B. Sarkari, N. Arefkhah, F. Ghorbani et al., "Seroprevalence of cystic Echinococcosis and related risk factors for infection among children in a rural community in Fars Province, Southern Iran," Clinical Epidemiology and Global Health, vol. 8, no. 1, pp. 13-16, 2020.

[8] R. Shahriarirad, A. Erfani, M. Eskandarisani, M. Rastegarian, and B. Sarkari, "Uncommon Locations of Cystic Echinococcosis: A Report of 46 Cases from Southern Iran," Surgery Research and Practice, vol. 2020, 6 pages, 2020.

[9] B. Sarkari, T. Naraki, M. A. Ghatee, S. Abdolahi Khabisi, and M. H. Davami, "Visceral Leishmaniasis in southwestern Iran: a retrospective clinico-hematological analysis of 380 consecutive hospitalized cases (1999-2014)," PLoS One, vol. 11, no. 3, article e0150406, 2016.

[10] M. A. Ghatei, G. R. Hatam, M. H. Hossini, and B. Sarkari, "Performance of latex agglutination test (KAtex) in diagnosis of visceral leishmaniasis in Iran," Iranian Journal of Immunology, vol. 6, no. 4, pp. 202-207, 2009.

[11] K. Ajilore, I. Atakiti, and K. Onyenankeya, "College students' knowledge, attitudes and adherence to public service announcements on Ebola in Nigeria: suggestions for improving future Ebola prevention education programmes," Health Education Journal, vol. 76, no. 6, pp. 648-660, 2017.

[12] N. Tachfouti, K. Slama, M. Berraho, and C. Nejjari, "The impact of knowledge and attitudes on adherence to tuberculosis treatment: a case-control study in a Moroccan region," Pan African Medical Journal, vol. 12, 2012.

[13] D. M. Bell and World Health Organization Working Group on Prevention of International and Community Transmission of SARS, "Public health interventions and SARS spread, 2003," Emerging Infectious Diseases, vol. 10, no. 11, pp. 1900-1906, 2004.

[14] M. F. Abdulhameed, I. D. Robertson, S. A. al-Azizz, and I. Habib, "Knowledge, attitudes, and practices of 50 patients with surgically treated cystic echinococcosis from Basrah Province, Iraq," Journal of Epidemiology and Global Health, vol. 8, no. 3-4, pp. 196-202, 2018.

[15] A. Khan, K. Naz, H. Ahmed et al., "Knowledge, attitudes and practices related to cystic echinococcosis endemicity in Pakistan," Infectious Diseases of Poverty, vol. 7, no. 1, p. 4, 2018. 
[16] J. Yin, Q. Gongsang, L. Wang, C. Li, and X. Wu, "Identification of vulnerable populations and knowledge, attitude, and practice analysis of echinococcosis in Tibet Autonomous Region of China," Environmental Research, vol. 190, p. $110061,2020$.

[17] D. Gebremichael, A. Feleke, G. Tesfamaryam, H. Awel, and Y. Tsigab, "Knowledge, attitude and practices of hydatidosis in Pastoral community with relation to public health risks in Ayssaita, northeastern of Ethiopia," Global Veterinaria, vol. 11, pp. 272-279, 2013.

[18] M. E. Ahmed, O. A. Hassan, A. K. Khalifa et al., "Echinococcosis in Tambool, Central Sudan: a knowledge, attitude and practice (KAP) study," International Health, vol. 10, no. 6, pp. 490494, 2018.

[19] H. Çakmur, L. Akoğlu, E. Kahraman, and M. Atasever, "Evaluation of farmers' knowledge-attitude-practice about zoonotic diseases in Kars, Turkey," Kafkas J Med Sci, vol. 5, no. 3, pp. 87-93, 2015.

[20] H. Özlü, M. Atasever, and M. A. Atasever, "Knowledge, attitude, and practices of cattle farmers regarding zoonotic diseases in Erzurum, Turkey," Austral journal of veterinary sciences, vol. 52, no. 3, pp. 79-85, 2020.

[21] B. B. Singh, R. Kaur, G. S. Gill, J. P. S. Gill, R. K. Soni, and R. S. Aulakh, "Knowledge, attitude and practices relating to zoonotic diseases among livestock farmers in Punjab, India," Acta Tropica, vol. 189, pp. 15-21, 2019.

[22] I. E. Buishi, E. M. Njoroge, O. Bouamra, and P. S. Craig, "Canine echinococcosis in Northwest Libya: assessment of coproantigen ELISA, and a survey of infection with analysis of risk-factors," Veterinary Parasitology, vol. 130, no. 3-4, pp. 223-232, 2005.

[23] I. El Berbri, M. J. Ducrotoy, A.-F. Petavy et al., "Knowledge, attitudes and practices with regard to the presence, transmission, impact, and control of cystic echinococcosis in Sidi Kacem Province, Morocco," Infectious Diseases of Poverty, vol. 4, no. 1, article 48, 2015.

[24] A. Keyhani, I. Sharifi, M. Bamorovat et al., "Epidemiological and molecular studies on Echinococcus granulosus from freeroaming dogs in Southeast Iran," Vet world, vol. 13, no. 4, pp. 739-745, 2019.

[25] D. Mehrabani, A. Oryan, and S. M. Sadjjadi, "Prevalence of Echinococcus granulosus infection in stray dogs and herbivores in Shiraz, Iran," Veterinary Parasitology, vol. 86, no. 3, pp. 217-220, 1999.

[26] P. M. Schantz, H. Wang, J. Qiu et al., "Echinococcosis on the Tibetan Plateau: prevalence and risk factors for cystic and alveolar echinococcosis in Tibetan populations in Qinghai Province, China," Parasitology, vol. 127, no. S1, pp. S109-S120, 2003.

[27] A. Possenti, R. Manzano-Román, C. Sánchez-Ovejero et al., "Potential risk factors associated with human cystic echinococcosis: systematic review and meta-analysis," PLoS Neglected Tropical Diseases, vol. 10, no. 11, article e0005114, 2016

[28] T. M. Galeh, A. Spotin, M. Mahami-Oskouei et al., "The seroprevalence rate and population genetic structure of human cystic echinococcosis in the Middle East: a systematic review and meta-analysis," International Journal of Surgery, vol. 51, pp. 39-48, 2018.
[29] M. Nasrieh, S. K. Abdel-Hafez, S. A. Kamhawi, P. S. Craig, and P. M. Schantz, "Cystic echinococcosis in Jordan: socioeconomic evaluation and risk factors," Parasitology Research, vol. 90, no. 6, pp. 456-466, 2003.

[30] A. Ito, C. Urbani, Q. Jiamin et al., "Control of echinococcosis and cysticercosis: a public health challenge to international cooperation in China," Acta Tropica, vol. 86, no. 1, pp. 3-17, 2003. 